\title{
INVESTIGATION OF THE 0.5-4 HZ LOW-FREQUENCY RANGE IN THE WAVE TRAIN ELECTRICAL ACTIVITY OF MUSCLES IN PATIENTS WITH PARKINSON'S DISEASE AND ESSENTIAL TREMOR
}

\author{
Olga S. Sushkova, Alexei A. Morozov \\ Kotelnikov Institute of Radioengineering and Electronics of RAS, http://www.cplire.ru/ \\ Moscow 125009, Russian Federation
}

\section{Alexandra V. Gabova \\ Institute of Higher Nervous Activity and Neurophysiology of RAS, http://ihna.ru/ \\ Moscow 117485, Russian Federation}

\begin{abstract}
Alexei V. Karabanov, Larisa A. Chigaleychik
FSBI Research Center of Neurology, https://www.neurology.ru/

Moscow 125367, Russian Federation

o.sushkova@mail.ru,morozov@cplire.ru,agabova@yandex.ru,doctor.karabanov@mail.ru, chigalei4ick.lar@ yandex.ru
\end{abstract}

Abstract. An investigation of the 0.5-4 Hz little-studied frequency range electromyograms (EMG) was performed in patients with Parkinson's disease (PD) and essential tremor (ET). In this frequency range, new neurophysiological regularities were revealed that were not previously described in the literature. There are statistically significant differences between groups of patients with PD/ET and a control group of subjects. A new method for analyzing wave train electrical activity of the muscles based on the wavelet analysis and ROC analysis was used. This method enables to study the time-frequency features of EMG signals in patients with PD and ET. The idea of the method is to find local maxima (that correspond to the wave trains) in the wavelet spectrogram and to calculate various characteristics describing these maxima: the leading frequency, the duration in periods, the bandwidth, the number of wave trains per second. The degree of difference of the group of patients from the control group of subjects is analyzed in the space of these parameters. ROC analysis is used for this purpose. The functional dependence of AUC (the area under the ROC curve) on the values of the bounds of the ranges of the parameters under consideration is investigated. This method is aimed at studying changes in the time-frequency characteristics (the shape) of signals including changes that are not related to the power spectral density of the signal. The application of the method allowed revealing new statistical regularities in EMG signals, which previously were not detected using standard spectral methods based on the analysis of the power spectral density of signals.

Keywords: Parkinson's disease, essential tremor, trembling hyperkinesis, electromyogram, EMG, tremor, wave trains, wavelet spectrogram

UDC 519.67, 612.8, 53.088

Bibliography - 39 references

Received 28.06.2019, accepted 30.06.2019

RENSIT, 2019, 11(2):225-236

DOI: 10.17725/rensit.2019.11.225

CONTENTS

1. INTRODUCTION (225)

2. Experimental Setting (228)

3. Signal Analysis Method (228)

4. Conclusion (233)

REFERENCES (234)

\section{INTRODUCTION}

Preclinical diagnosis is very important for the treatment of Parkinson's disease (PD) and essential tremor (ET). Although PD and ET have been intensively studied in recent decades, the preclinical indicators of these movement disorders remain to be established 
[1].

EMG signal investigations are objective methods for assessing neuromuscular function in PD and ET. Surface EMG signals are often analyzed using amplitude and spectral methods. These methods are used to measure the degree of muscle activation and fatigue. The neuromuscular function can also be measured indirectly by analyzing the tremor of the extremities that it controls. This can be done using motion sensors, such as accelerometers [2].

Usually, the frequency range below 4 $\mathrm{Hz}$ is not investigated in EMG, since it is considered that it is impossible to find statistically significant differences between groups of patients and healthy subjects in this range. In the EEG, the frequency ranges of theta (4-7 Hz), alpha (8-12 Hz), beta (13$24 \mathrm{~Hz})$, and gamma $(25-48 \mathrm{~Hz})[3,4]$ are mainly studied. It is rare to find papers where the delta (1-4 Hz) range is studied in EEG [5]. In EMG, mostly studied frequency varies from 5 to $18 \mathrm{~Hz}$ [6]. In the works devoted to the study of tremor coherence on EMG with tremor components on EEG, ranges above $4 \mathrm{~Hz}$ are also studied [7]. The resting tremor itself in patients with PD is commonly studied on EMG in the classical frequency range $4-7 \mathrm{~Hz}$, and essential tremor is studied in patients with ET in the frequency range from 4 to $12 \mathrm{~Hz}$ [8]. However, there are works in which the frequency range below $4 \mathrm{~Hz}$ on the EMG is still being studied. In particular, the authors of [9] are engaged in the search for the characteristics of the basal ganglia of the brain associated with tremor in movement in patients with PD.

Mathematical approaches used for the analysis of EMG in PD include spectral methods (average frequency, power fraction in certain frequency bands) [10,11], analysis of the characteristics of bursts of EMG (quantity, amplitude, duration, and frequency) [12 15], analysis of the morphology of the EMG signal [16], and methods of nonlinear analysis of EMG [10].

Studies that analyze EMG signals are focused on analyzing the regularity of hand tremor and their low-frequency coherence in PD. In particular, it was shown in [2] that tremor in patients with $\mathrm{PD}$ is more regular (that is, with lower entropy) than physiological tremor measured in neurologically healthy subjects (frequencies from 1 to $1000 \mathrm{~Hz}$ were investigated, but significant differences were discovered only in the frequency ranges from 8 to $12 \mathrm{~Hz}$ and from 20 to $25 \mathrm{~Hz}$ ). In addition, in work [2], it was shown that the tremor regularity of patients with PD is reduced due to medicament treatment and deep brain stimulation [17] (the frequency range from 1 to $8 \mathrm{~Hz}$ was studied). EMG coherence studies have shown that the coherence between EMG of the extensor muscles and EMG of the flexor muscles is higher for patients with PD than for healthy subjects [18].

Measurements of EMG and tremor of the limbs can be used for an objective and quantitative assessment of neuromuscular function and movement disorders in PD. In the future, they can help in the diagnosis and subsequent treatment of PD. In addition, such measurements can improve the understanding of the neurological mechanisms of the disease [19]. According to the authors of the paper [19], these measurements are still rarely used in the evaluation of PD. Since EMG is a spike (a wave of a pulsed form), according to the authors of [19], nonlinear and morphological methods can be more effective in analyzing EMG than traditionally used methods (amplitudes and average, 
median frequencies, etc.). The method used in our work is non-linear, since the calculation of extremes of the wavelet spectrogram is a non-linear operation, and indirectly involves analyzing changes in the waveform. However, the method does not involve the extraction and analysis of any signal samples, as it is implemented in the classical morphological analysis of the signals. Of course, if one does not consider the wavelets as such samples.

An approach to the study of neurological diseases based on a comparison of electromyographic signals of the extensor muscles and flexor muscles was proposed in [20]. It was shown that the power spectral density of the EMG signal in the $1-30 \mathrm{~Hz}$ frequency range in the ulnar flexion of the hand is significantly higher in the PD group compared with the ET group [20]. However, these results were obtained by standard methods (Fourier spectra, wavelets, etc.). Note that in the paper [11], where frequency ranges above $5 \mathrm{~Hz}$ are studied, there was a significant positive correlation between the power ratio in the frequency range from 5 to $15 \mathrm{~Hz}$ of the EMG agonist signal and the UPDRS-Motor indicator (the Unified Parkinson's Disease Rating Scale), as well as a significant negative correlation between the fraction of power in the frequency range from 15 to $30 \mathrm{~Hz}$ and the UPDRS-Motor indicator.

In work [21], the electromyographic method of registration and a quantitative assessment of the disorders of muscular activity of the person arising in connection with motor pathology have been offered. The basis of the method is the selection of the frequency range of the EMG spectrum corresponding to the motor act and spectral analysis of signals in the selected range. The developed method was used in studies of extrapyramidal disorders in parkinsonism and ET. The main disadvantage of this method of EMG analysis is a long measurement time necessary for the subsequent averaging (up to 20 one-minute records).

Earlier, we developed a method for analyzing the wave train electrical activity of the cerebral cortex, based on wavelet analysis and ROC analysis [22,23]. The idea of this method of analysis is in that an electroencephalogram (EEG) is considered as a set of wave trains [24]. In contrast to works on the detection of the electrical activity of one or two specific types, such as alpha spindles [25] and sleep spindles [26-31], we analyze any type of the wave train electrical activity in the cerebral cortex over a wide frequency range. In addition, we consider the wave train as a typical component of EEG, but not as a special kind of EEG signals. Previously, such an approach was proposed in $[32,33]$.

To analyze the EMG signals, the developed signal analysis algorithm $[22,23]$ was modified [34]. The method of analysis considered in this paper is based on the statistical analysis of wavelet spectrograms, a new method of visualizing the results of statistical analysis, and a new wave train detection algorithm in the EMG signals. In particular, an additional step of smoothing the wavelet spectrograms of signals was added to the signal analysis algorithm. Smoothing is required because the standard fast algorithms for calculating wavelets have the following problem: wavelet spectrograms (when processing signals of complex shape) are inevitably contaminated by digital artifacts (outliers and highfrequency vibrations). These artifacts can be mistakenly recognized as "wave trains" in EMG.

The use of the method of analysis of 
wave train electrical activity allowed us to reveal new neurophysiological regularities in patients with PD and ET in the poorly studied frequency range $0.5-4 \mathrm{~Hz}$ in EMG signals.

\section{EXPERIMENTAL SETTING}

Data from untreated (that is, previously not taking specific medicine) patients with PD and ET in the early stages were compared with data from healthy volunteers. Note that the group of patients with PD included patients at the first stage of PD on the Hoehn and Yahr scale with left-hand tremor (9 people) and patients at the first stage of PD with right-hand tremor (11 people), 20 people in total. The number of patients with ET was 13 people. The number of healthy volunteers was 8 people. All patients and healthy volunteers were right-handed. No statistically significant differences between the ages of patients and healthy volunteers were found. EMG electrodes were located both on the outer sides of the arms, on the extensor muscles, and on the inner sides of the arms, on the flexor muscles. The surface EMG signals were recorded in a special pose of the subject. The subject was sitting in a chair, his arms were straight in front of him, and his legs were quietly on the floor. Eyes were closed during all recordings. To record the EMG, the Neuron-Spectrum-5 multifunctional 41-channel complex for the neurophysiological studies (Neurosoft Company) was used. The sampling rate of EMG was $500 \mathrm{~Hz}$. For EMG, a high-pass filter with the $0.5 \mathrm{~Hz}$ cut-off frequency and the $50 \mathrm{~Hz}$ notch filter were used. In addition, the Butterworth filter with the 60-240 Hz bandwidth was applied to EMG. After filtering, the Hilbert transform was applied to the EMG signals to compute the envelope of the signals. The duration of each record was about two minutes. Records were analyzed as is, without selecting individual areas in the signal.

\section{SIGNAL ANALYSIS METHOD}

For the study, the method of analysis of the wave train electrical activity of the muscles was used, based on wavelet analysis and ROC analysis [22,23]. The idea of the method is to search for local maxima ("wave trains") on the wavelet spectrogram and calculate various characteristics describing these maxima: the leading frequency of the wave trains, the duration of the wave trains in periods, the width of the wave train frequency band, the number of wave trains per second. The degree of difference in the group of patients with PD and ET from the control group of subjects in the space of these parameters is analyzed. For this, ROC analysis is used. The functional dependence of AUC (the area under the ROC curve) on the values of the bounds of the ranges of the parameters under consideration is investigated. This method is aimed at studying changes in the time-frequency characteristics (the shape) of signals, including those not related to changes in the power spectral density of the signal.

The tremor in patients in the first stage of PD, studied in this work, appears only on one side of the body. In contrast to PD, in patients with ET, tremor appears on both sides of the body at once. Further, we will conditionally call the PD patient's hand, on which the tremor manifests, as "tremor" hand and we will conventionally call the second hand as "healthy" hand.

Let us consider an example of a wave train detected by our method on the wavelet 
$\overline{\text { MEDICAL PHYSICS }}$

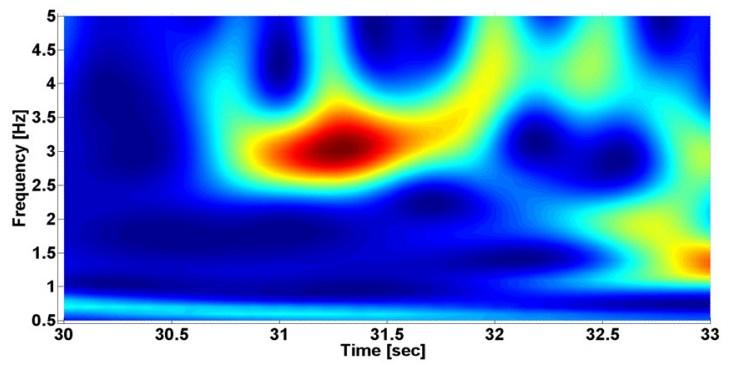

Fig. 1. A wave train in the wavelet spectrogram of the EMG signal envelope.

spectrogram of an EMG signal on the patient's "healthy" (left) hand with the tremor of the right side of the body on the extensor muscle (Fig. 1). The central frequency of the wave train is $3 \mathrm{~Hz}$, the signal clearly localized in time and in frequency.

The envelope of the EMG signal, which was used to calculate the spectrogram in Fig. 1, is represented in Fig. 2. On the signal envelope, one can see 4 periods of the wave train envelope. Note that the signal envelope is used to analyze tremor in accordance with the classical method [21], however, to calculate the signal envelope, we apply the Hilbert transform, but not signal detection. For Fig. 2, after calculating the envelope, additional filtering of the signal was applied with the 0.5-7 Hz band-pass filter to improve the signal image.

In Fig. 3, one can see the original EMG signal. Note that it is almost impossible to observe the investigated wave train in the original signal; therefore classical methods

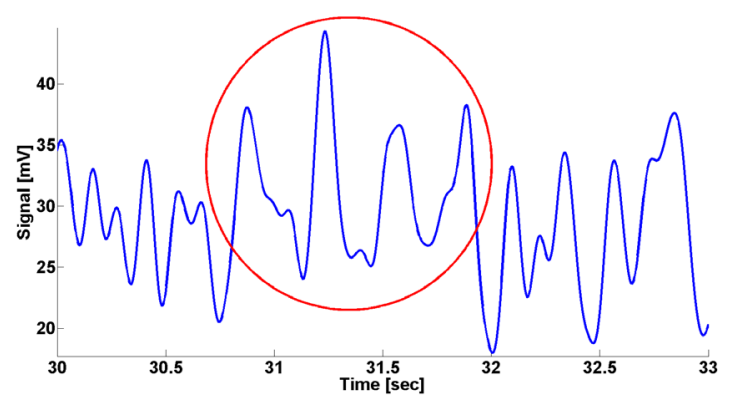

Fig. 2. The EMG signal envelope. The wave train is indicated by the red circle.
INVESTIGATION OF THE 0.5-4 HZ LOW-FREQUENCY RANGE IN THE WAVE TRAIN ELECTRICAL ACTIVITY...

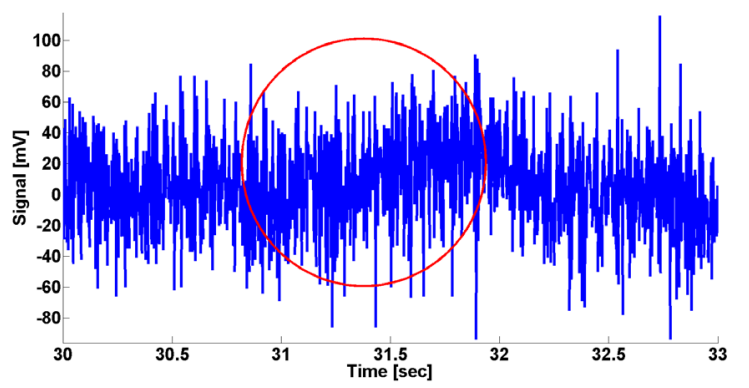

Fig. 3. The original EMG signal. The wave train is indicated by the red circle.

of morphological analysis of signals are not applicable to the analysis of these signals.

In this paper, we study the number of wave trains (per second) in the $0.5-4 \mathrm{~Hz}$ frequency range in EMG of patients with PD and ET. The number of wave trains is compared with the healthy subject data using special AUC-diagrams and Mann-Whitney non-parametric statistical test. A detailed description of the AUC diagrams is given in [23,24,34-39].

\section{RESULTS}

Statistically significant differences between the patient groups and the control group of subjects were found both on the "tremor" hands and on the "healthy" hands of patients with PD (with a tremor on the left hand and with a tremor on the right hand) and in patients with ET on both hands.

We calculated wave trains in the frequency range from 0.5 to $4 \mathrm{~Hz}$ for EMG signals (both for extensor muscles and flexor muscles) in each patient with PD (patients with left-hand tremor and patients with right-hand tremor were investigated separately), every patient with ET, and every healthy volunteer. From these data, AUC values were calculated for different frequency ranges in the interval from 0.5 to $4 \mathrm{~Hz}$.

The frequency AUC diagram for the extensor muscles of the "tremor" left hands 


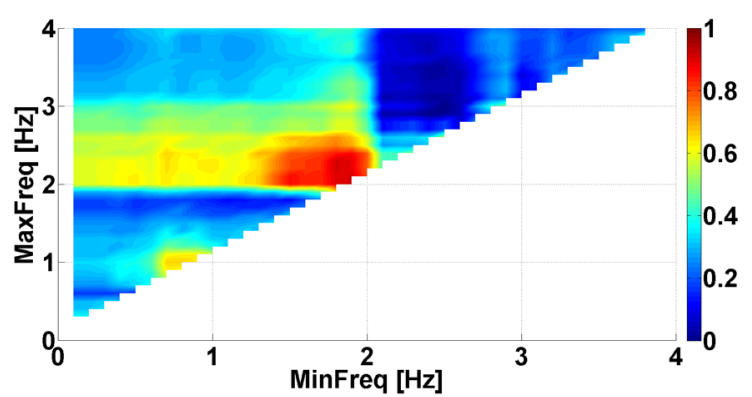

Fig. 4. An AUC diagram for extensor muscles. EMG of the left ("tremor") hand of patients with PD. The abscissa is the lower bound of the frequency ranges. The ordinate is the upper bound of the frequency ranges. The frequencies from 0.5 to $4 \mathrm{~Hz}$ with the $0.1 \mathrm{~Hz}$ step are considered. of patients with PD is presented in Fig. 4.

The blue color in the AUC diagram means that the number of wave trains in patients is less than in healthy subjects. Red color indicates that the number of wave trains in patients is greater than in healthy subjects. In the diagram in Fig. 4, pronounced regularities (red and blue areas) are visible in the frequency ranges $0.1-1.8 \mathrm{~Hz}$ (a blue spot), 1.8-2.3 Hz (a red spot), and 2.1-3.9 Hz (a blue spot). Let's perform a statistical analysis of the number of wave trains per second using the MannWhitney test.

The $\mathrm{p}$-values (the level of statistical significance) for extensor muscles for patients with PD (for "tremor" hands and "healthy" hands) and for patients with ET are listed in Table 1. Statistically significant differences were found for extensor muscles in the frequency ranges $0.1-1.8 \mathrm{~Hz}$ (the blue spot), 1.8-2.3 Hz (the red spot), and 2.1-3.9 Hz (the

The $p$-values for the extensor muscles.

\begin{tabular}{|l|l|l|l|l|l|l|}
\hline $\begin{array}{l}\text { Frequ- } \\
\text { ency } \\
\text { ranges, } \\
\mathrm{Hz}\end{array}$ & $\begin{array}{l}\text { PD, } \\
\text { left } \\
\text { "tre- } \\
\text { mor" } \\
\text { hand }\end{array}$ & $\begin{array}{l}\text { PD, } \\
\text { right } \\
\text { "heal- } \\
\text { thy" } \\
\text { hand }\end{array}$ & $\begin{array}{l}\text { PD, } \\
\text { left } \\
\text { "heal- } \\
\text { thy" } \\
\text { hand }\end{array}$ & $\begin{array}{l}\text { PD, } \\
\text { right } \\
\text { tre- } \\
\text { mor" } \\
\text { hand }\end{array}$ & $\begin{array}{l}\text { ET, } \\
\text { left } \\
\text { hand }\end{array}$ & $\begin{array}{l}\text { ET, } \\
\text { right } \\
\text { hand }\end{array}$ \\
\hline $0.1-1.8$ & 0.02 & $\begin{array}{l}\text { not sig- } \\
\text { nificant }\end{array}$ & $\begin{array}{l}\text { not sig- } \\
\text { nificant }\end{array}$ & 0.01 & $\begin{array}{l}\text { not sig- } \\
\text { nificant }\end{array}$ & $\begin{array}{l}\text { not sig- } \\
\text { nificant }\end{array}$ \\
\hline $1.8-2.3$ & 0.003 & $\begin{array}{l}\text { not sig- } \\
\text { nificant }\end{array}$ & $\begin{array}{l}\text { not sig- } \\
\text { nificant }\end{array}$ & $\begin{array}{l}\text { not sig- } \\
\text { nificant }\end{array}$ & $\begin{array}{l}\text { not sig- } \\
\text { nificant }\end{array}$ & $\begin{array}{l}\text { not sig- } \\
\text { nificant }\end{array}$ \\
\hline $2.1-3.9$ & 0.001 & $\begin{array}{l}\text { not sig- } \\
\text { nificant }\end{array}$ & $\begin{array}{l}\text { not sig- } \\
\text { nificant }\end{array}$ & 0.01 & $\begin{array}{l}\text { not sig- } \\
\text { nificant }\end{array}$ & $\begin{array}{l}\text { not sig- } \\
\text { nificant }\end{array}$ \\
\hline
\end{tabular}

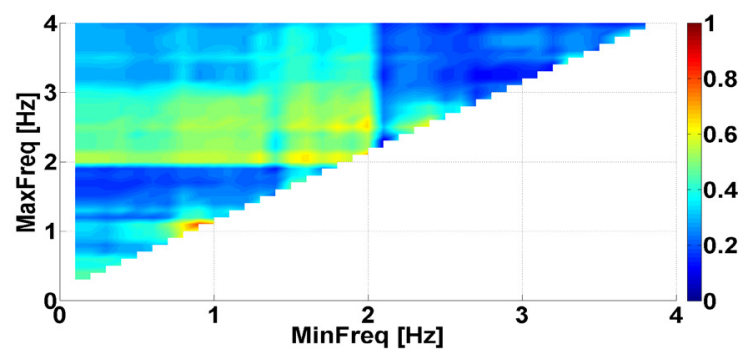

Fig. 5. An AUC diagram for extensor muscles. EMG of the right ("tremor") band of patients with PD. Along the axes, frequencies are similar to Fig. 4.

blue spot) only on the "tremor" hands of the patients with PD.

The frequency AUC diagram for the extensor muscles of the "tremor" right hands of the patients with PD is presented in Fig. 5. The results of the statistical analysis and AUC diagrams demonstrate that on the left and right "tremor" hands of the patients with PD, similar regularities are observed, however, on the right "tremor" hands these regularities are less pronounced. Statistically significant differences in the considered frequency ranges were not found in patients with ET. This indicates that the observed regularities are specific for $\mathrm{PD}$.

A comparison of the parameters of the tremor in the extensor muscles and flexor muscles of patients with PD and ET is of great interest. Frequency AUC diagrams for the flexor muscles of the "tremor" arms of the patients with PD are shown in Fig. 6 and 7.

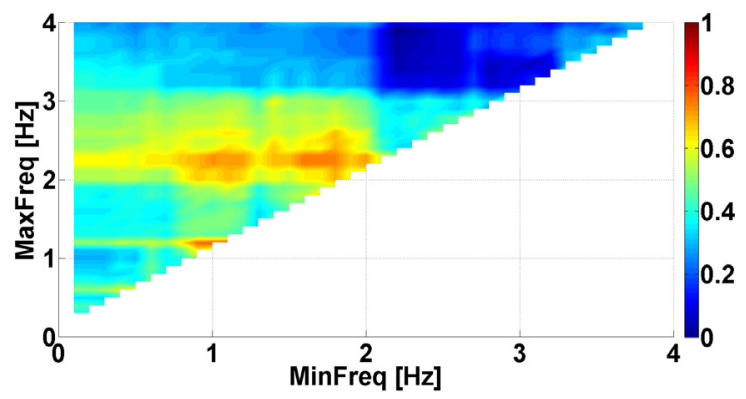

Fig. 6. An AUC diagram for flexor muscles. EMG of the left ("tremor") hand of patients with PD. Along the axes, frequencies are similar to Fig. 4. 


\section{MEDICAL PHYSICS}

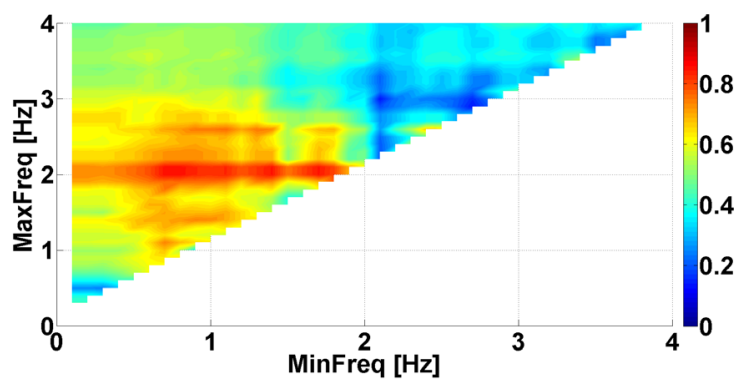

Fig. 7. An AUC diagram for flexor muscles. EMG of the right ("tremor") hand of patients with PD. Along the axes, frequencies are similar to Fig. 4.

Frequency AUC diagrams for the flexor muscles of the "healthy" hands of the patients with PD are shown in Fig. 8 and 9.

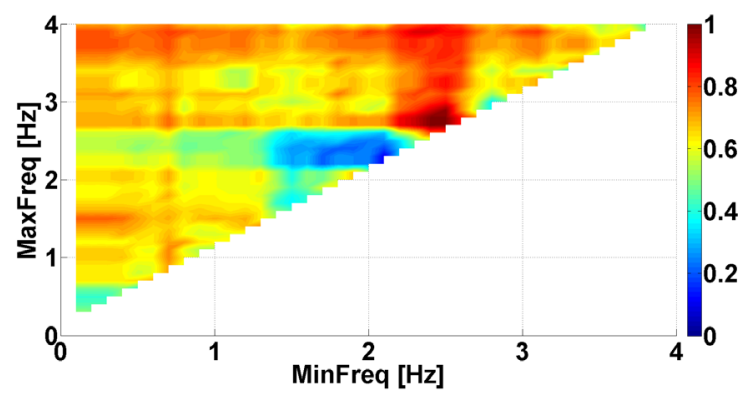

Fig. 8. An AUC diagram for flexor muscles. EMG of the right ("bealthy") hand of patients with PD. Along the axes, frequencies are similar to Fig. 4.

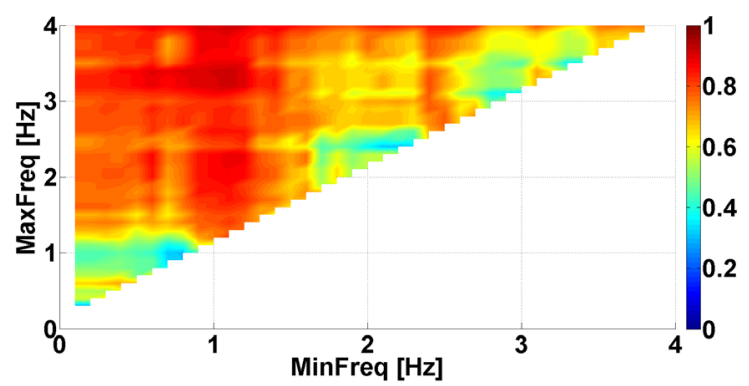

Fig. 9. An AUC diagram for flexor muscles. EMG of the left ("bealthy") hand of patients with PD. Along the axes, frequencies are similar to Fig. 4.

Unlike the extensor muscles, there are differences in the flexor muscles not only in the "tremor" hands but also in the "healthy" hands of the patients with PD. The following frequency ranges were analyzed: $1.1-3.1 \mathrm{~Hz}$ (a red spot on the AUC diagram on the left "healthy" hand of the patients with PD), 2.1-3 Hz (a blue spot on the AUC diagram
INVESTIGATION OF THE 0.5-4 HZ LOW-FREQUENCY RANGE IN THE WAVE TRAIN ELECTRICAL ACTIVITY...

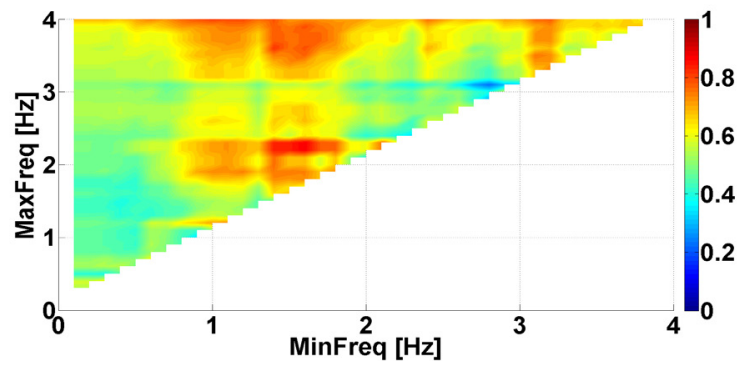

Fig. 10. An AUC diagram for flexor muscles. EMG of the left hand of patients with ET. Along the axes, frequencies are similar to Fig. 4.

on the right "tremor" hand of the patients with PD), and 2.2-3.9 Hz (a blue spot on the AUC diagram on the left "tremor" hand of the patients with PD). In addition, the frequency range 1.6-2.3 Hz was analyzed, because it corresponds to a red spot on the AUC diagram on the left hand of the patients with ET (see Fig. 10). The AUC diagram on the right hand of the patients with ET (see Fig. 11) also contains regularities, but in this paper, they are not considered because it was discovered that they are not specific for ET.

The $\mathrm{p}$-values for the flexor muscles for the patients with PD and ET are shown in Table 2. For the flexor muscles, statistically significant differences were found in the frequency ranges $1.1-3.1 \mathrm{~Hz}$ (the red spot), 2.1-3 Hz (the blue spot), and 2.2-3.9 Hz (the blue spot). Statistically significant differences in ET were found in the 1.6-2.3 Hz frequency range (the red spot), but only in the left hand. Thus, specific regularities were found for PD and ET. However, these regularities are

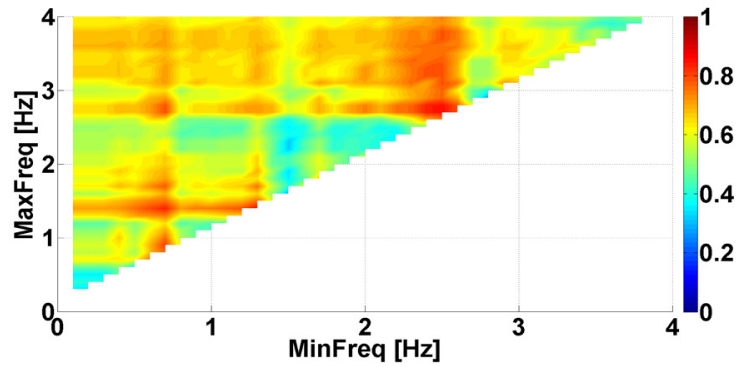

Fig. 11. An AUC diagram for flexor muscles. EMG of the right hand of patients with ET. Along the axes, frequencies are similar to Fig. 4. 
Table 2

The $p$-values for the flexor muscles.

\begin{tabular}{|l|l|l|l|l|l|l|}
\hline $\begin{array}{l}\text { Frequ- } \\
\text { ency } \\
\text { ranges, } \\
\mathrm{Hz}\end{array}$ & $\begin{array}{l}\text { PD, } \\
\text { left } \\
\text { "tre- } \\
\text { mor" } \\
\text { hand }\end{array}$ & $\begin{array}{l}\text { PD, } \\
\text { right } \\
\text { "heal- } \\
\text { thy" } \\
\text { hand }\end{array}$ & $\begin{array}{l}\text { PD, } \\
\text { left } \\
\text { "heal- } \\
\text { thy" } \\
\text { hand }\end{array}$ & $\begin{array}{l}\text { PD, } \\
\text { right } \\
\text { tre- } \\
\text { mor" } \\
\text { hand }\end{array}$ & $\begin{array}{l}\text { ET, } \\
\text { left } \\
\text { hand }\end{array}$ & $\begin{array}{l}\text { ET, } \\
\text { right } \\
\text { hand }\end{array}$ \\
\hline $1.1-3.1$ & $\begin{array}{l}\text { not sig- } \\
\text { nificant }\end{array}$ & $\begin{array}{l}\text { not sig- } \\
\text { nificant }\end{array}$ & 0.006 & $\begin{array}{l}\text { not sig- } \\
\text { nificant }\end{array}$ & $\begin{array}{l}\text { not sig- } \\
\text { nificant }\end{array}$ & $\begin{array}{l}\text { not sig- } \\
\text { nificant }\end{array}$ \\
\hline $1.6-2.3$ & $\begin{array}{l}\text { not sig- } \\
\text { nificant }\end{array}$ & $\begin{array}{l}\text { not sig- } \\
\text { nificant }\end{array}$ & $\begin{array}{l}\text { not sig- } \\
\text { nificant }\end{array}$ & $\begin{array}{l}\text { not sig- } \\
\text { nificant }\end{array}$ & 0.005 & $\begin{array}{l}\text { not sig- } \\
\text { nificant }\end{array}$ \\
\hline $2.1-3.0$ & $\begin{array}{l}\text { not sig- } \\
\text { nificant }\end{array}$ & $\begin{array}{l}\text { not sig- } \\
\text { nificant }\end{array}$ & $\begin{array}{l}\text { not sig- } \\
\text { nificant }\end{array}$ & 0.006 & $\begin{array}{l}\text { not sig- } \\
\text { nificant }\end{array}$ & $\begin{array}{l}\text { not sig- } \\
\text { nificant }\end{array}$ \\
\hline $2.2-3.9$ & 0.00008 & 0.01 & $\begin{array}{l}\text { not sig- } \\
\text { nificant }\end{array}$ & $\begin{array}{l}\text { not sig- } \\
\text { nificant }\end{array}$ & $\begin{array}{l}\text { not sig- } \\
\text { nificant }\end{array}$ & $\begin{array}{l}\text { not sig- } \\
\text { nificant }\end{array}$ \\
\hline
\end{tabular}

observed in different frequency ranges in different hands of the patients; this makes it difficult to use them for the differential diagnosis of PD and ET.

AUC diagrams were computed to compare the extensor muscles and the flexor muscles of the subjects (see Fig. 12 and 13). These diagrams are interesting because regularities in the "healthy" hands of patients with PD are observed. Two distinct frequency ranges were found in which the number of wave trains in the extensor muscles and flexor muscles differs: 1.8-3.9 Hz (a blue spot) and 2.1-2.5 Hz (a red spot). The p-values are given in Table 3. Statistically significant differences were found between the extensor muscles and the flexor muscles in both frequency ranges. There were no statistically significant differences in ET.

The found regularities on the "healthy" hands of the patients with PD are of

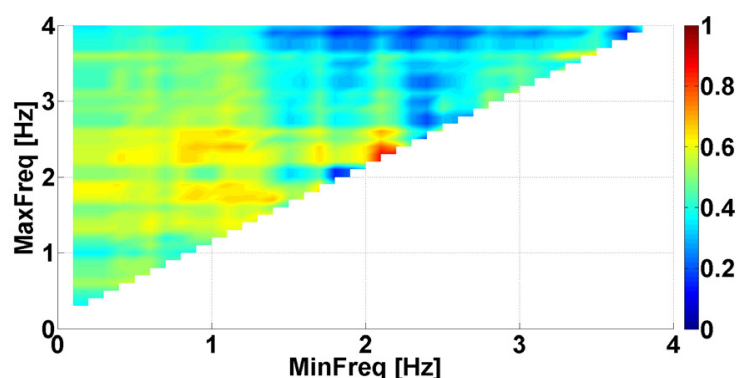

Fig. 12. An AUC diagram based on a comparison of extensor muscles with flexor muscles of the "bealthy" right hands of patients with PD. Along the axes, frequencies are similar to Fig. 4.

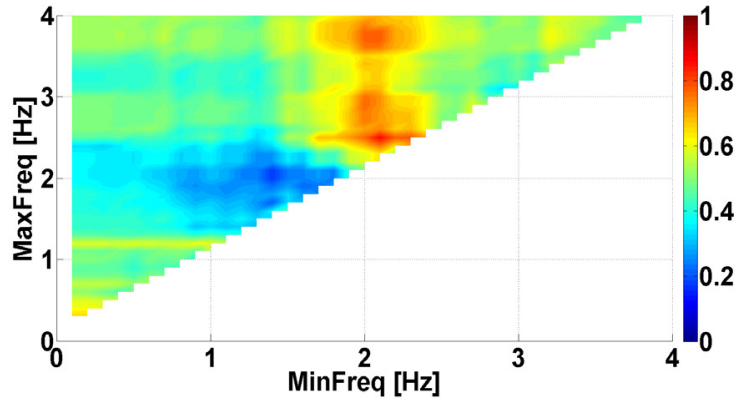

Fig. 13. An AUC diagram based on a comparison of extensor muscles with flexor muscles of the "healthy" left hands of patients with PD. Along the axes, frequencies are similar to Fig. 4.

considerable interest for early diagnosis of PD because the "healthy" hands of patients with PD can be used as a model of the processes occurring at the preclinical stages of PD.

\section{CONCLUSION}

A new method of exploratory data analysis was developed. This method involves calculating AUC values and non-parametric testing of statistical hypotheses to detect significant differences in the characteristics of electrical "wave train" activity of muscles. A detailed analysis of the data of patients with Parkinson's disease and essential tremor in the poorly studied frequency range 0.5$4 \mathrm{~Hz}$ was carried out. Statistically significant differences from the control group of subjects were found both in the "tremor" hands and in the "healthy" hands of the patients. It was demonstrated that the analysis of patients with Parkinson's disease using surface EMG

Table 3

The $p$-values for the comparison of the extensor muscles and the flexor muscles.

\begin{tabular}{|l|l|l|l|l|l|l|}
\hline $\begin{array}{l}\text { Frequ- } \\
\text { ency } \\
\text { ranges, } \\
\mathrm{Hz}\end{array}$ & $\begin{array}{l}\text { PD, } \\
\text { left } \\
\text { "tre- } \\
\text { mor" } \\
\text { hand }\end{array}$ & $\begin{array}{l}\text { PD, } \\
\text { right } \\
\text { "heal- } \\
\text { thy" } \\
\text { hand }\end{array}$ & $\begin{array}{l}\text { PD, } \\
\text { left } \\
\text { "heal- } \\
\text { thy" } \\
\text { hand }\end{array}$ & $\begin{array}{l}\text { PD, } \\
\text { right } \\
\text { tre- } \\
\text { mor" } \\
\text { hand }\end{array}$ & $\begin{array}{l}\text { ET, } \\
\text { left } \\
\text { hand }\end{array}$ & $\begin{array}{l}\text { ET, } \\
\text { right } \\
\text { hand }\end{array}$ \\
\hline $1.8-3.9$ & $\begin{array}{l}\text { not sig- } \\
\text { nificant }\end{array}$ & 0.008 & $\begin{array}{l}\text { not sig- } \\
\text { nificant }\end{array}$ & $\begin{array}{l}\text { not sig- } \\
\text { nificant }\end{array}$ & $\begin{array}{l}\text { not sig- } \\
\text { nificant }\end{array}$ & $\begin{array}{l}\text { not sig- } \\
\text { nificant }\end{array}$ \\
\hline $2.1-2.5$ & $\begin{array}{l}\text { not sig- } \\
\text { nificant }\end{array}$ & $\begin{array}{l}\text { not sig- } \\
\text { nificant }\end{array}$ & 0.003 & $\begin{array}{l}\text { not sig- } \\
\text { nificant }\end{array}$ & $\begin{array}{l}\text { not sig- } \\
\text { nificant }\end{array}$ & $\begin{array}{l}\text { not sig- } \\
\text { nificant }\end{array}$ \\
\hline
\end{tabular}


on the extensor muscles and flexor muscles gives different results; differences between the extensor muscles and flexor muscles in patients with ET were not detected. Found regularities in EMG can be useful for early diagnosis of Parkinson's disease.

It can be assumed that wave trains in the $0.5-4 \mathrm{~Hz}$ frequency range reflect the increased electrical activity of the muscle fiber groups that make up the muscles. The obtained results indicate an individual picture of frequency characteristics in the $0.5-4 \mathrm{~Hz}$ frequency range for specific diseases, which can be useful for the differential diagnosis of PD and ET.

Parkinson's disease is a systemic disease, and manifestations of this disease include impaired muscle tone, both in the shaking hands and non-shaking hands. The reason for this is in that, due to the disease, the reciprocal (cross) connections and the downward effect of the extrapyramidal system on the segmental level of tone control (alpha motoneurons, etc.) of the muscles are disrupted. The harmonious work of the agonists/antagonist muscle groups is violated. Identification of these changes allows determining the degree of decompensation from the "healthy", intact side, and also allows predicting the clinical manifestation of focal neurological symptoms. Monitoring of these changes can be used as a promising prognostic parameter of decompensation and an assessment of the effectiveness of a specific treatment.

The application of the developed signal analysis method allowed us to identify new regularities in the EMG signals that previously could not be detected using standard spectral methods based on the analysis of the power spectral density of the signals.

\section{ACKNOWLEDGMENTS}

The authors are grateful to the corresponding member of RAS S.N. Illarioshkin for helping with the work. The work was carried out within the framework of the state task. The study was supported by the scholarship of the President of the Russian Federation to young scientists and graduate students No. SP-5247.2018.4 and partially was supported by the Russian Foundation for Basic Research in the framework of the research project No. 18-37-20021.

\section{REFERENCES}

1. Meigal AY, Rissanen SM, Tarvainen MP, Airaksinen O, Kankaanp M, Karjalainen PA. Non-linear EMG parameters for differential and early diagnostics of Parkinson's disease. Frontiers in neurology, 2013, 4:135.

2. Rissanen SM, Kankaanpää M, Meigal A, Tarvainen MP, Nuutinen J, Tarkka IM, Airaksinen O, Karjalainen PA. Surface EMG and acceleration signals in Parkinson's disease: feature extraction and cluster analysis. Medical \& biological engineering \& computing, 2008, 46(9):849858.

3. Herz DM, Florin E, Christensen MS, Reck C, Barbe MT, Tscheuschler MK, TittgemeyerM, SiebnerHR, Timmermann L. Dopamine replacement modulates oscillatory coupling between premotor and motor cortical areas in Parkinson's disease. Cerebral cortex, 2013, 24(11):28732883.

4. Timmermann L, Florin E, Reck C. Pathological cerebral oscillatory activity in Parkinson's disease: a critical review on methods, data and hypotheses. Expert review of medical devices, 2007, 4:651-661.

5. Chung JW, Burciu RG, Ofori E, Coombes SA, Christou EA, Okun MS, Hess CW, Vaillancourt DE. Beta-band oscillations in the supplementary motor cortex are 
modulated by levodopa and associated with functional activity in the basal ganglia. NeuroImage: clinical, 2018, 19:559571.

6. Caviness JN, Shill HA, Sabbagh MN, Evidente VG, Hernandez JL, Adler CH. Corticomuscular coherence is increased in the small postural tremor of Parkinson's disease. Movement disorders: official journal of the Movement Disorder Society, 2006, 21(4):492-499.

7. Holobar A, Gallego JÁ, Kranjec J, Rocon E, Romero JP, Benito León J, Pons J, Glaser V. Motor unit-driven identification of pathological tremor in electroencephalograms. Frontiers in neurology, 2018, 9:879.

8. Joundi RA, Brittain JS, Jenkinson N, Green AL, Aziz T. Rapid tremor frequency assessment with the iPhone accelerometer. Parkinsonism \& related disorders, 2011, 17(4):288-290.

9. Burgess JG, Warwick K, Ruiz V, Gasson MN, Aziz TZ, Brittain JS, Stein J. Identifying tremor-related characteristics of basal ganglia nuclei during movement in the Parkinsonian patient. Parkinsonism \& related disorders, 2010, 16(10):671-675.

10. Fattorini L, Felici F, Filligoi G, Traballesi M, Farina D. Influence of high motor unit synchronization levels on non-linear and spectral variables of the surface EMG. Journal of neuroscience methods, 2005, 143(2):133-139.

11. Robichaud JA, Pfann KD, Vaillancourt DE, Comella CL, Corcos DM. Force control and disease severity in Parkinson's disease. Movement disorders, 2005, 20(4):441450.

12. Flament D, Vaillancourt D, Kempf T, Shannon K, Corcos D. EMG remains fractionated in Parkinson's disease, despite practice-related improvements in performance. Clinical neurophysiology, 2003, 114(12):2385-2396.

13. Pfann KD, Buchman AS, Comella CL, Corcos DM. Control of movement distance in Parkinson's disease. Movement disorders, 2001, 16(6):1048-1065.

14. Robichaud JA, Pfann KD, Comella CL, Brandabur M, Corcos DM. Greater impairment of extension movements as compared to flexion movements in Parkinson's disease. Experimental brain research, 2004, 156(2):240-254.

15. Robichaud JA, Pfann KD, Comella CL, Corcos DM. Effect of medication on EMG patterns in individuals with Parkinson's disease. Movement disorders, 2002, 17(5):950-960.

16. Rissanen S, Kankaanpää M, Tarvainen MP, Nuutinen J, Tarkka IM, Airaksinen $\mathrm{O}$, Karjalainen PA. Analysis of surface EMG signal morphology in Parkinson's disease. Physiological measurement, 2007, 28(12):1507.

17. Sturman MM, Vaillancourt DE, Metman LV, Bakay RA, Corcos DM. Effects of subthalamic nucleus stimulation and medication on resting and postural tremor in Parkinson's disease. Brain, 2004, 127(9):2131-2143.

18. Vaillancourt DE, Newell KM. The dynamics of resting and postural tremor in Parkinson's disease. Clinical neurophysiology, 2000, 111(11):2046-2056.

19. Valls-Solé J, Valldeoriola F. Neurophysiological correlate of clinical signs in Parkinson's disease. Clinical neurophysiology, 2002, 113(6):792-805.

20. Ivanova EO, Fedin PA, Brutyan AG, Ivanova-Smolenskaya IA, Illarioshkin SN. Analysis of tremor activity of antagonist muscles in essential tremor and Parkinson's 
diseases. Neurological journal, 2014, 4:11-18. 21. Andreyeva EA, Khutorskaya OE. Spektral'nyy metod analiza elektromiograficheskoy aktivnosti myshts [Spectral method for the analysis of muscle electromyographic activity]. Moscow, Nauka Publ., 1987, p. 192.

22. Sushkova OS, Morozov AA, Gabova AV. A method of analysis of EEG wave trains in early stages of Parkinson's disease. Proceedings of International Conference on Bioinformatics and Systems Biology (BSB2016), IEEE, 2016, pp. 1-4.

23. Sushkova OS, Morozov AA, Gabova AV. Data Mining in EEG Wave Trains in Early Stages of Parkinson's Disease. Advances in Soft Computing. MICAI 2016. Lecture Notes in Computer Science, 2017, 10062:403412.

24. Sushkova OS, Morozov AA, Gabova AV, Karabanov AV. Data mining in EEG wave trains in early stages of Parkinson's disease. Proceedings of the 12th RussianGerman Conference on Biomedical Engineering, 2016, pp. 80-84.

25. Lawhern V, Kerick S, Robbins KA. Detecting alpha spindle events in EEG time series using adaptive autoregressive models. BMC neuroscience, 2013, 14:101, http://www.biomedcentral.com/14712202/14/101.

26. Parekh A, Selesnick I, Rapoport D, Ayappa I. Sleep spindle detection using time-frequency sparsity. IEEE Signal Processing in Medicine and Biology Symposium, IEEE, Philadelphia, PA, 2014, pp. 1-6.

27. O'Reilly C, Nielsen T. Automatic sleep spindle detection: benchmarking with fine temporal resolution using open science tools. Frontiers in buman neuroscience, 2015, 9:353, http://doi.org/10.3389/ fnhum.2015.00353.
28. Huupponen E, Clercq WD, GómezHerrero G, Saastamoinen A, Egiazarian K, Värri A, Vanrumste B, Vergult A, Huffel SV, Paesschen WV, Hasan J, Himanen SL. Determination of dominant simulated spindle frequency with different methods. Journal of neuroscience methods, 2006, 156:275-283.

29. Nonclercq A, Urbain C, Verheulpen D, Decaestecker C, Bogaert PV, Peigneu P. Sleep spindle detection through amplitude-frequency normal modelling. Journal of neuroscience methods, 2013, 214:192-203.

30. Jaleel A, Ahmed B, Tafreshi R, Boivin DB, Streletz L, Haddad N. Improved spindle detection through intuitive preprocessing of electroencephalogram. Journal of neuroscience methods, 2014, 233:112.

31. Camilleri TA, Camilleri KP, Fabri SG. Automatic detection of spindles and $\mathrm{K}$-complexes in sleep EEG using switching multiple models. Biomedical signal processing and control, 2014, 10:117-127.

32. Zhirmunskaya EA. Klinicheskaya elektroentsefalografiya (tsifry, gistogrammy, illyustratsiz) [Clinical electroencephalography (numbers, histograms, illustrations)]. Moscow, Mezhotraslevoy nauchnoissledovatel'skiy inzhenernotekhnologicheskiy tsentr "Skan" Publ., 1993.

33. Obukhov YV, Korolev MS, Gabova AV, Kuznetsova GD, Ugrumov MV. Method of early encephalographic diagnostics of Parkinson disease. Patent no. 2484766 Russian Federation, 20.06.2013.

34. Sushkova OS, Morozov AA, Gabova AV, Karabanov AV. Investigation of Surface EMG and Acceleration Signals of Limbs' Tremor in Parkinson's Disease Patients 
Using the Method of Electrical Activity Analysis Based on Wave Trains. Advances in Artificial Intelligence. Proceedings of 16 th Ibero-American Conference on AI, Eds Simari GR, Ferme E, Segura FG and Melquiades JAR. Springer International Publishing, 2018, pp. 253-264.

35. Sushkova OS, Morozov AA, Gabova AV, Karabanov AV. Primenenie metoda analiza vspleskoobraznoy elektricheskoy aktivnosti mozga dlya vyyavleniya osobennostey EEG patsientov na ranney stadii bolezni Parkinsona [Application of brain electrical activity burst analysis method for detection of EEG characteristics in the early stage of Parkinson's disease]. S.S. Korsakov journal of neurology and psychiatry, 2018, 118(7):4548, (in Russ.).

36. Sushkova OS, Morozov AA, Gabova AV, Karabanov AV. An investigation of the specificity of features of early stages of Parkinson's disease obtained using the method of cortex electrical activity analysis based on wave trains. Journal of physics: conference series, 2018, 1096:012078.

37. Sushkova OS, Morozov AA, Gabova AV. Proc. 13th International Conference on SignalImage Technology \& Internet-Based Systems (SITIS), IEEE, 2017, pp. 168-172.

38. Sushkova OS, Morozov AA, Gabova AV. Development of a method of analysis of EEG wave packets in early stages of Parkinson's disease. Proceedings of the InternationalConference "Information Technology and Nanotechnology" (ITNT-2016), CEUR Workshop Proceedings, 2016, 1638:681690. DOI: 10.18287/1613-0073-20161638-681-690.

39. Sushkova OS, Morozov AA, Gabova AV, Karabanov AV. Issledovanie problemy mnozhestvennogo sravneniya pri analize vspleskoobraznoy elektricheskoy aktivnosti myshts u patsientov s bolezniyu Parkinsona [Investigation of the multiple comparisons problem in the analysis of the wave train electrical activity of muscles in Parkinson's disease patients]. Proceedings of ITNT-2019: V International Conference and Youth School "Information Technologies and Nanotechnologies", May 2124, 2019. Ed. V.A. Fursov. Samara, New Technique, 2019, Vol. 4: Data Science, pp. 329-337 (in Russ.). 